\title{
Challenging accepted ethical beliefs
}

This month's issue presents arguments on three longstanding ethical issues: prostitution, euthanasia and organ donation. It also addresses three issues perhaps more directly linked to daily practice across clinical care and research: resource allocation, consent, and, in an interesting pair of papers, how a clinician's own experiences might affect their ethical judgement and therefore clinical care.

In a provocative article, Ole Martin Moen argues that our increasing acceptance of casual sex, that is, sexual encounters which do not involve an emotional connection, render our assumption that prostitution is always harmful out of date. If one form of impersonal encounter is acceptable, then why not another? Naturally, prostitution involves some degree of risk of harm. However, he argues that many occupations we do accept are likewise risky, or are also subject to similar objections to prostitution. He allows there is one remaining harm, which is genuine today, but which is open to change: the legal and social stigma, which we impose on prostitution due to our mistaken beliefs (see page 73, Editor's choice).

Our two invited commentators, Anderson (see page 82) and McDougall (see page 83) focus on the empirical evidence of harm. When a new drug is developed, a plausible theory as to its effects, mechanism and safety is required. We might test that in a computer model. But until it is tested in real life, we cannot know its real benefits or harms. The same might be true of ethical arguments. As McDougall says:

\begin{abstract}
Moen presents a compelling argument that the exchange of sex for money need not be intrinsically harmful to the seller, but for the individuals actually involved in prostitution, does this conclusion really matter?
\end{abstract}

The reader might ask why a journal of medical ethics is publishing an article on prostitution. There are clearly potential and alleged physical and psychological health harms to sex workers and their clients. However, the Journal was pleased to publish this article for two other reasons.

When I was a young doctor doing my $\mathrm{Ph} \mathrm{D}$ in bioethics, I did locum work to supplement my scholarship. One of my colleagues offered me a very lucrative and efficient locum which he could no longer cover but recommended: performing tests for STDs for sex workers in brothels. I declined, partly I believe because of my own cultural and implicit bias. Moen's article, in the tradition of good medical ethics, challenges conventional societal stereotypes, calling for reasons to justify current practice and attitudes. It also provides excellent, coherent arguments that are a fine example of method in medical ethics.

Organ donation and the selling of organs have raised a number of legal and ethical concerns as our previous special issue 'The Human Body as Property? Possession, Control and Commodification' explored. But between selling and altruistically donating there are many motivations for donation. In the UK, the response has been to demand that altruism is a requirement of any organ donation. But we face a well-documented organ shortage. Moorlock, Ives and Draper argue that "while altruistic motivation may be desirable, it is not necessary" (see page 134). Even if concerns about risk of harm to the seller (and indeed the buyer) might outweigh the benefits of selling organs, when it comes to motivations to freely donate, altruistic or otherwise, in a life and death situation, we might do well to follow the old adage, "don't look a gift horse in the mouth".

In another follow up discussion to a special issue, this time 'Withdrawing Artificial Nutrition and Hydration', we have a set of contrasting papers on euthanasia. Tak Kwong Chan and George Lim Tipoe argue that in the case $\operatorname{Re} M$, where a court decided that the patient, $M$, who had remained in a minimally conscious state for 8 years, should continue to be kept alive via artificial nutrition and hydration, despite her family's wishes. Key to the decision was the distinction between cases of persistent vegetative state (PVS), such as Bland, which had previously caused $\mathrm{M}$ to state to her family her wish to have treatment removed in the same situation, and her diagnosis of minimally conscious state (MCS). Whilst the family felt that this made no difference to what M's wishes would have been, in the court's view this allowed a greater emphasis to be placed on indications of her taking enjoyment, or at least being 'comfortable' at some times during her life in MCS, and, in the context of sanctity of life argued that artificial nutrition and hydration should not be withdrawn. Tak Kwong Chan and George Lim Tipoe take a similar view to the judge in their assessment of the "benefits of being alive". Sensations may in themselves be a benefit or of value to the patient in MCS. Indeed they go further than the judgement in $\operatorname{Re} M$ to argue that such benefits (or at least the impossibility of assessing on behalf of the patient the benefits) should not only determine that withdrawal of nutrition and hydration is not in the patient's best interests, but, were the resources to be needed for a patient with a better prognosis to return to full consciousness, it would be a 'grave discrimination' to deny treatment to a patient with MCS in their favour (see page 131).

The question of what we can know about another's suffering or the value of their life is raised by Varelius in a very different set of euthanasia cases, those with 'existential suffering' or who are 'tired of life'. Whilst we cannot experience anyone else's pain, physical or mental, there is an argument that distinguishes a doctor's understanding of and duty towards physical pain, from her understanding of 'existential suffering', and indeed whether she has a duty to work towards the relief of such suffering. It is a slightly different case for patients with MCS where the doctor does not know the extent of their suffering, or of their pleasures. In this case, the patient can explain how they feel. But should she assist such a patient to end their suffering via voluntary euthanasia (or should the law allow her to do so?). For Varelius, there is no distinction between physical and existential suffering in terms of how qualified the doctor may be to recognise its severity and likelihood of relief (see page 104).

Young responds that this proposal is impractical. In the vast majority of countries, euthanasia for existential suffering is politically impossible, and linking existential and physical suffering is is likely to be counter productive for those who wish to see euthanasia legalised in their jurisdictions. Secondly, simply because physicians 
may have the ability to make judgements over this type of suffering, it does not imply that this falls under their remit as medical care. Indeed the Dutch Supreme court has ruled that it does not (see page 108).

Both Young and I have alternative suggestions for Varelius. Young suggests that for this category of patients therapy or counselling is required. It may be that there are patients whose suffering will not be relieved, and who may face lifelong suffering. For these patients, suicide is an option.

I argue on the other hand that there could be a legally and ethically warranted form of assisted suicide open to all patients already, regardless of the nature of their illness or suffering, voluntary palliated starvation (see page 110). Choosing such a route would not be easy for patients, physicians, families or caregivers. But in the absence of alternatives, it is one that is already in use among some patients. It was the route that Tony Nicklinson was prepared to take after the High Court blocked his request for assisted suicide. Like Nicklinson, however, I believe there should be a legal alternative to this.

One issue that interacts with many of the major ethical debates of our time is paradoxically often ignored within those debates: rationing. Inevitably there are limits to what can be provided in healthcare: organs, beds in intensive care, physician time are all limited resources. The chance of recovery for a PVS patient might be vanishingly slim, but if resources were unlimited those chances might be worth waiting for. Likewise, if organs were plentiful we could be picky about pure motivations for giving. Daniel Stech and Marion Danis address this issue head on in tandem with the austerity politician's favourite buzzword, inefficiency. If a perfect world would see unlimited resources for healthcare, the good enough world might be one where inefficiency was entirely eradicated before any rationing was introduced. Sadly of course, this is still something to aspire to. Strech and Danis have come up with a pathway to the good enough world: benchmarking efficiency. These benchmarks, based on evidence "should state explicitly how much inefficiency shall be reduced in a reasonable time range and why these efforts are 'sufficient'" (see page 89). In this context, they argue that concurrent rationing is allowable.

A resource that is limited for both patients and their caregivers is time. Should you be told if you risk wasting yours? That is the question posed by Wertheimer in this issue. There has been much debate over how much information should be given for informed consent. Too much can be as problematic as too little. Onora O’Neill argued previously in this journal "it would be ethically wrong to require patients to handle a form as complicated as a mortgage application at a difficult time in their lives. Not all patients want to be burdened with all the detail, while others require an in depth understanding." 1 Nevertheless, it is key that all relevant matters are covered. One item that Wertheimer argues is not covered is the risk that not enough patients will be recruited for the study to proceed. That is, those who do sign up should be informed of the risk that they are wasting their time at the outset (see page 127).

Finally, an interesting pair of research papers investigates the interaction between ethical decision making and professional practice. A survey of Portuguese doctors and nurses found that ethical decision making in ICU (such as the decision to withdraw treatment) led to increased burnout amongst nurses, but not amongst doctors, with one possible cause identified as lower involvement by nurses in the decision- making process (see page 97). In the second survey, a comparison was made between the attitudes of fetal care paediatric specialists and maternal-fetal medicine specialists towards abortion of pregnancies due to congenital abnormalities in the foetus. They found that responses amongst the two groups varied, with the foetal care paediatric specialists group less likely to view foetal abnormalities as a reason to terminate a preganancy, and less likely to believe that the impact on the family, whether emotional, economic or social should be taken into account (see page 117).

Competing interests None.

Provenance and peer review Commissioned; internally peer reviewed.

\section{REFERENCE}

1 O'Neill O. Symposium on consent and confidentiality: some limits of informed consent. J Med Ethics 2003;29:4-7. 